\title{
Hyperekplexia: Treatment of a Severe Phenotype and Review of the Literature
}

\author{
Aleksandra Mineyko, Sharon Whiting, Gail E. Graham
}

\begin{abstract}
Hyperekplexia is a rare disorder caused by autosomal dominant or recessive modes of inheritance and characterized by episodes of exaggerated startle. Five causative genes have been identified to date. The syndrome has been recognized for decades and due to its rarity, the literature contains mostly descriptive reports, many early studies lacking molecular genetic diagnoses. A spectrum of clinical severity exists. Severe cases can lead to neonatal cardiac arrest and death during an episode, an outcome prevented by early diagnosis and clinical vigilance. Large treatment studies are not feasible, so therapeutic measures continue to be empiric. A marked response to clonazepam is often reported but refractory cases exist. Herein we report the clinical course and treatment response of a severely affected infant homozygous for an SLC6A5 nonsense mutation and review the literature summarizing the history and genetic understanding of the disease as well as the described comorbidities and treatment options.
\end{abstract}

RÉSUMÉ: Hyperekplexie : traitement d'un phénotype sévère et revue de la littérature. L'hyperekplexie est une maladie caractérisés par des épisodes de réaction exagérée de sursaut et dont le mode d'hérédité peut être dominant ou récessif. À ce jour, cinq gènes différents ont été identifiés. Le syndrome est connu depuis plusieurs dizaines d'années et, à cause de sa rareté, la littérature fait état surtout de descriptions de cas dont plusieurs, surtout les premières, ne comportent pas de diagnostic moléculaire. La sévérité clinique est très variable et, chez les cas sévères, la maladie peut entraîner un arrêt cardiaque dans la période néonatale et le décès, ce qui peut être prévenu par un diagnostic précoce et une surveillance clinique. Son traitement demeure empirique parce qu'il n'est pas possible d'effectuer de grandes études sur ce sujet. Bien qu'une excellente réponse au clonazépam soit souvent rapportée, il existe des cas résistants à ce traitement. Nous rapportons ici l'évolution clinique et la réponse thérapeutique chez un bébé sévèrement atteint, homozygote pour une mutation non-sens de SLC6A5, et nous revoyons la littérature portant sur l'histoire et l'explication génétique de la maladie ainsi que sur les comorbidités décrites et les options thérapeutiques.

Can. J. Neurol. Sci. 2011; 38: 411-416

Hyperekplexia is a syndrome of exaggerated startle response to tactile, auditory, or other stimuli. ${ }^{1}$ Patients can present early in the neonatal period with episodes of stiffening that can be so severe as to cause apnea and death,,$^{2-9}$ a phenotype often referred to as "stiff-baby syndrome." ${ }^{5}$ With time, the life-threatening manifestations of hyperekplexia are replaced by startle responses that are characterized by stiffening and falls. ${ }^{2,5,8,10}$ Less severely affected patients experience excessive startle without significant stiffening. ${ }^{11}$ Onset of symptoms can occur after the neonatal period and can be into adulthood. ${ }^{12,13}$

Hyperekplexia is understood to be a monogenic, though heterogeneous, disorder. Autosomal dominant, autosomal recessive, and apparently sporadic forms (that are more likely the result of de novo mutations) have been recognized. ${ }^{14}$ Mutations responsible for hyperekplexia have been found in the alpha 1 subunit of the glycine receptor gene (GLRA1), ${ }^{15}$ the beta glycine receptor subunit gene $(G L R B),{ }^{16}$ the presynaptic sodiumand chloride-dependent glycine transporter 2 gene
(SLC6A5), ${ }^{17,18}$ the glycinergic clustering molecule gephryn $(G P H N),{ }^{19}$ and in one patient, in the collybistin gene (ARHGEF9). ${ }^{20}$ At times, a mutation cannot be found ${ }^{11,21,22}$ suggesting the presence of additional causative genes that have not yet been described. Many earlier case descriptions predate these molecular findings $1,3-6,10,13,23-27$ and therefore cannot be

From the Department of Genetics (GEG); Division of Neurology, Department of Pediatrics (AM, SW), Children's Hospital of Eastern Ontario, Ottawa, Ontario, Canada.

Received October 29, 2010. Final Revisions Submitted December 22, 2010. Correspondence to: Aleksandra Mineyko, Division of Neurology, Department of Pediatrics, Alberta Children's Hospital, 2888 Shaganappi Trail NW, Calgary, Alberta, T3B 6A8, Canada. 
used for genotype-phenotype correlations. Historically on the basis of clinical severity, hyperekplexia has been divided into major and minor forms. ${ }^{1,25}$ The coexistence of these forms in the same family suggests that other factors, possibly variants in different genes, may influence the expression of the phenotype.

Given the rarity of this condition, there are no large trials addressing its most effective management. Most reports have described marked improvement with clonazepam $2,4,7,8,16,25,28-31$ but many other medications have been used when treatment with clonazepam has not been effective. ${ }^{12,13,27,28,31,32}$

This report describes the clinical course and treatment response of a severely affected infant who is homozygous for an SLC6A5 nonsense mutation. Such genotype/phenotype descriptions may ultimately help clinicians tailor management to their patients.

\section{Case Report}

Our patient was a term female born to a 27-year-old G4P4L4. The family moved to Canada from Pakistan at 22 weeks gestation. Two prenatal ultrasounds were normal. In retrospect, the mother reported abnormal rhythmic movements in utero. The baby girl was born at term by vaginal delivery without instrumentation. No resuscitation was required and Apgars were 9 at one and ten minutes. Birth weight was $3422 \mathrm{~g}$ (50th centile) and head circumference was $34 \mathrm{~cm}$ (50th centile).

The parents noted "startle" episodes in hospital, but she was discharged at 24 hours of age. Overnight they noted recurrent "seizures" during which she would stiffen and tremble for 20 seconds to one minute, her face turning "black". They brought the baby, now 40 hours-of-age, to the emergency department after a prolonged episode. While in the emergency department she had multiple episodes associated with apnea. She was treated with lorazepam, a loading dose of phenobarbital (40 mg/kg), and was admitted to the neonatal intensive care unit (NICU). She was febrile (38.8 C rectally) with otherwise stable vital signs and was started on empiric antibiotics.

The NICU staff noted recurrent episodes that began with exaggerated responses to acoustic, tactile, or visual stimuli and were followed by tachycardia, stiffening and jerky movements of the whole body. Without intervention, the patient became apneic with decreased oxygen saturation. The spells could be aborted by folding the patient's upper body towards the lower body with flexion of spine/neck or holding her in this position tightly. Oxygen and manual ventilation were at times necessary.

Magnetic resonance imaging of the head was unremarkable. Blood work, including investigations for inborn errors of metabolism, was normal. Blood and cerebrospinal fluid (CSF) cultures were negative and antibiotics were stopped. Serial EEGs were normal; captured events did not correlate with electrographic seizures on EEG. The diagnosis of hyperekplexia was queried and confirmed clinically when it was determined that attacks could be elicited by tapping on the philtrum.

Treatment was initiated with clonazepam at 0.01 $\mathrm{mg} / \mathrm{kg} / \mathrm{day}(\mathrm{d})$ and slowly increased to $0.1 \mathrm{mg} / \mathrm{kg} / \mathrm{d}$ as episodes continued. At this maximal dosage the patient was too sedated to feed. Decreasing the clonazepam resulted in a significant episode that required transfer back to the NICU. Clonazepam was replaced with valproic acid $(10 \mathrm{mg} / \mathrm{kg} / \mathrm{d})$ without success. Clobazam was added and increased to a maximum of 1.75 $\mathrm{mg} / \mathrm{kg} / \mathrm{d}$ and valproic acid, which had never produced significant improvement, was tapered and discontinued. On clobazam, the patient was again significantly sedated and the dose was decreased to $0.3 \mathrm{mg} / \mathrm{kg} / \mathrm{d}$. Nitrazepam was added at $1 \mathrm{mg} / \mathrm{kg} / \mathrm{d}$ and improvement was noted. Given initial improvement with clonazepam and it simply not being tolerated at higher doses, clobazam was tapered and discontinued and clonazepam restarted at a lower dose of $0.07 \mathrm{mg} / \mathrm{kg} / \mathrm{d}$. With this combination of benzodiazepines, the patient stabilized. She continued to have daily spells but these did not require intervention or result in apneas. Dosage adjustments allowed for discharge at four months-of-age on nitrazepam $1 \mathrm{mg} / \mathrm{kg} / \mathrm{d}$ and clonazepam 0.06 $\mathrm{mg} / \mathrm{kg} / \mathrm{d}$.

The patient was initially tried with oral feeds but because of a lack of interest in sucking a gastrostomy tube was placed and later successfully removed at 17 months-of-age. Over the next two years, the patient had two emergency department visits for spells and one brief admission at 20 months-of-age for a significant episode that required her parents to administer CPR at home. She continues to have four to five episodes per week of stiffening and jerking when tired or hungry. These are not associated with cyanosis or apnea. Due to these mild episodes her dose of clonazepam was increased to $0.125 \mathrm{mg}$ in the morning and $0.25 \mathrm{mg}$ at night. Her nitrazepam dose was maintained at $2.5 \mathrm{mg}$ BID.

\section{Development}

Given the prolonged and complicated stay in hospital, the difficulty with oral feeding, and the diagnosis of hyperekplexia, the patient was assessed and followed by child developmental services. She was assessed using the Alberta Infant Motor Scale (AIMS) and scored below average at four and seven months. She began walking at 16 months-of-age and physiotherapy was no longer required by 22 months-of-age. Fine motor skills were normal. Her first speech-language assessment occurred at 22 months-of-age using the Rossetti Infant Toddler Language Scale. Her skills were judged to be between 15-18 months for language comprehension and 18-21 months for gesture and play and expressive language. The patient was always described as a sociable child with good eye contact, appropriate play interests, and normal interactions with her surroundings. In summary, by two years-of-age, her fine motor and social skills were ageappropriate. Her gross motor development, initially mildly delayed, had normalized. Her language development however, remained delayed.

\section{Family History}

The patient's parents were first cousin Pakistani Muslims. In addition to two healthy boys, they had a previous daughter, born in Pakistan after an uneventful term pregnancy and vaginal delivery weighing $3.3 \mathrm{~kg}$ with unconcerning Apgar scores. Her parents recall episodes of rhythmic jerking of her upper arms, legs, and body resembling "shivering," that were associated with stridor and a dark blue facial color in the first 24 hours-of-life. Her medical records document "tonic-clonic" seizures from Day 2 of life lasting 20-25 seconds and occurring two to three times per day. Between 10 and 15 days-of-life, her seizures increased in frequency, severity, and duration. In response to her 
respiratory symptoms, choanal stenosis and larygomalacia were ruled out. At three months-of-age, an EEG demonstrated diffuse slowing (interpreted as possibly indicative of a metabolic etiology), but no clear epileptiform activity. Cranial ultrasound, magnetic resonance imaging (MRI) and computed tomogram (CT) of the brain were all reportedly normal. Her medical records document normal growth and development, making a metabolic etiology unlikely. At five months-of-age after a three day asymptomatic period, she died while having a 45 minute "seizure" at home. She had no symptoms of intercurrent illness at the time. No etiology for her seizures was ever found and an autopsy was not performed. In retrospect, it is highly probable that she had hyperekplexia.

\section{Genetic Testing}

Neither the parents nor either of the two male siblings had clinical evidence of hyperekplexia. Consistent with parental consanguinity, our patient was found to be homozygous for a nonsense mutation, R439X, in the SLC6A5 gene. The functional impact of this mutation, which introduces a stop codon, is currently being studied.

\section{History}

The first mention of exaggerated startle in the medical literature dates back to 1880 when Beard published his observations of the "Jumping Frenchmen of Maine". ${ }^{33} \mathrm{He}$ described 50 cases of exaggerated startle, echolalia, and "suggestibility". In 1884, a similar syndrome was described in patients from Siberia. ${ }^{34}$ Gilles de la Tourette's interest in these reports led to the evolution of the syndrome that now bears his name. ${ }^{35}$ Little literature on the topic of exaggerated startle exists after $1912 .{ }^{36}$ In 1965 , the topic was reviewed by Stevens who reported three new cases. ${ }^{37}$ The differences between the startle disorders were later elucidated in the 1980s and it is now clear that these early descriptions did not refer to the condition we now know as hereditary hyperekplexia. . $^{2,38,39}$

The term hyperexplexia was first used in 1966 by Suhren et $\mathrm{al}^{1}$ who described a Dutch family with an autosomal dominant form of exaggerated startle reflex. The features were described as: (1) hereditary, with an autosomal dominant mode of transmission; (2) excessive startle by stimuli that do not result in a response from normal individuals; (3) startle is exaggerated by emotional tension, nervousness, fatigue; (4) consciousness remains intact; (5) neonates demonstrate generalized hypertonia from birth; (6) feeding problems do not occur and development is not retarded but motor activities proceed more slowly; (7) disorder severity varies during life with remission or progression of disease; (8) generalized jerks at falling asleep; (9) exaggerated brainstem reflexes; (10) higher prevalence of inguinal, umbilical, and epigastric hernias. Within the Dutch pedigree, there were individuals with a "minor" form of this disorder who only had the exaggerated startle and none of the other features.

In 1967 , Gastaut ${ }^{36}$ reported 12 patients with "essential startle disease" with no family history. As in the hereditary form of hyperekplexia, patients had an exaggerated startle to auditory or tactile stimuli that could be so severe as to cause them to fall. These patients did not seem to have a neonatal history of hypertonicity.
In 1980 Andermann et $\mathrm{al}^{25}$ described two kindreds with hyperekplexia. By this time, the two forms of the disorder, a major and a minor form, were well accepted. As both forms could be seen in a single family, they were thought to represent different phenotypic expression of the same gene.

In the 1990s, Tijssen et al re-evaluated the Dutch family once the linkage of hyperekplexia to chromosome $5 q$ was established. He found linkage to the area only in family members that fit the criteria for the "major" form. ${ }^{40}$ In a later publication the authors went on to describe the "minor" form of hyperekplexia that was seen in the remaining members of the Dutch pedigree. ${ }^{41}$

\section{Genetics}

The importance of genetic factors in the heritance of hyperekplexia has been recognized since the first descriptions of the disorder. Prior to identification of the responsible genes, autosomal dominant inheritance with incomplete penetrance and variable expressivity was recognized.,25 In 1992, linkage analysis performed in a large family revealed that the disease locus was linked to markers along the long arm of chromosome $5 .^{42,43}$ In 1993 mutations were identified in the gene encoding the alpha 1 subunit of the inhibitory glycine receptor (GLRAl) in affected individuals. ${ }^{44}$

The mammalian glycine receptor (GlyR) is a heterooligomeric protein complex consisting of five transmembrane proteins located at the cytoplasmic face of the postsynaptic membrane. The receptor forms a ligand-gated chloride channel $^{45,46}$ that when activated, results in membrane hyperpolarization, and thus, synaptic inhibition in the brainstem and spinal cord. ${ }^{47}$

There exist numerous descriptions in the literature of autosomal dominant pedigrees with mutations in GLRA1. At least one non-penetrant GLRAl mutation has been reported. ${ }^{48}$ There are also rare cases of hyperekplexia caused by homozygosity ${ }^{49-52}$ or compound heterozygosity ${ }^{52,53}$ for recessive GLRA1 mutations.

However, GLRAI mutations could not be identified in all affected individuals. ${ }^{11,21,22}$ The assumption of genetic heterogeneity for hyperekplexia was confirmed in 2002, when the first mutation in the $\beta$-subunit of the glycine receptor $(G L R B)$ was identified in one of 22 individuals with sporadic hyperekplexia. ${ }^{16}$ This patient was found to be a compound heterozygote for a splice site and a missense mutation in GLRB, confirming an autosomal recessive mechanism for mutations in this gene.

With time it became apparent that mutations in other proteins that interact with the glycine receptor could also be responsible for hyperekplexia. Gephyrin, an anchoring protein, interacts with the $\beta$-subunit of the glycine receptor at the post-synaptic membrane. ${ }^{54}$ One individual with a missense mutation in the gephyrin gene $(G P H N)$ was found to have clinical evidence of hyperekplexia. ${ }^{19}$

Collybistin is required for proper translocation of gephyrin to the cell membrane. One patient with epilepsy and hyperekplexia was found to have a mutation in the collybistin (ARHGEF9) gene. ${ }^{20}$

Finally, presynaptic glycine transporters are responsible for the reuptake of glycine at the synapse. ${ }^{55}$ Both heterozygous and compound heterozygous mutations of the glycine transporter 2 
gene (GLYT2 or SLC6A5) have been shown to result in hyperekplexia. ${ }^{17,18}$

\section{Comorbidities}

\section{Neonatal Apnea and Death}

Although the onset of symptoms of hyperekplexia has been reported in all age groups, symptoms most often begin at birth. As described by Suhren et $\mathrm{al}^{1}$ and Andermann et al, ${ }^{25}$ neonates present with hypertonicity, exaggerated startle, and at times complications of inguinal or umbilical hernias. Cases of neonatal death in patients with hyperekplexia secondary to apnea, cardiac arrhythmias or cardiac arrest were reported early in the understanding of the disorder. ${ }^{1,3,4,6,56-58}$ Hyperekplexia has also been suggested as one of the possible etiologies for sudden infant death syndrome (SIDS). ${ }^{3,57}$

\section{Feeding Difficulties}

Feeding difficulties, as were experienced by our patient, have also been reported as a complication of hyperekplexia. ${ }^{2,4}$ In one case series feeding difficulties were noted in $20 \%$ of patients. These were reported to improve with successful treatment of the attacks. $^{2}$

\section{Developmental Delays}

Most patients with hyperekplexia are described as developmentally normal. 1,2,4,5,7,9,10,16,20,25,30,32,43,59-63 Gross motor development may be slowed and is thought to be secondary to the hypertonicity and/or frequent falls. . $^{2,4,5,7,9,10,16,20,25,27,30,32,43,59-}$ ${ }^{63}$ Other delays in development have been reported but detailed descriptions are lacking. ${ }^{7,22,51,64,65}$

\section{Treatment}

\section{Benzodiazepines}

\section{Clonazepam}

Clonazepam is the most commonly recommended treatment for hyperekplexia. Several authors report significant improvement with doses of $0.03-0.2 \mathrm{mg} / \mathrm{kg} / \mathrm{d}^{2,4,7,8,16,25,28-31}$ Clonazepam is a gamma-aminobutyric acid receptor a1 (GABARAl) agonist, enhancing GABA-gated chloride channel function and presumably compensating for the defective glycinegated chloride channel function in hyperekplexia. ${ }^{66}$

The study determining the linkage of the gene for hyperekplexia to chromosome $5 \mathrm{q}$ described a family with autosomal dominant hyperekplexia. Sixteen family members were treated successfully with clonazepam. Only patients with severe symptoms were treated. Three of them were children. Patients had significant improvement but not complete resolution of symptoms with a dosage regimen of a maximum of $3 \mathrm{mg}$ daily for adults and $1.5 \mathrm{mg}$ daily for children. Sedation side effects were reported as mild and transient. ${ }^{43}$

Other treatments have been tried in more difficult cases. Unfortunately, the rarity of the disorder precludes large studies of efficacy. One double-blind, placebo controlled, cross-over study that included four patients revealed that patients on clonazepam had reduced startle activity compared to vigabatrin as measured by startle to auditory stimuli. ${ }^{67}$
Despite often dramatic response to clonazepam, $, 2,4-$ $9,16,23,25,26,29,30,49-51,53,67$ there are other reports that have found clonazepam to be less effective..$^{5,11,16,27,31,61}$ Saenz-Lope et al ${ }^{27}$ found clonazepam ineffective in their three patients but had some success with the use of valproic acid and a combination of hydroxytryptophan and piracetam. A series of 44 patients found clonazepam ineffective in four patients. ${ }^{57}$ A combination of clonazepam and diazepam was ineffective in treating a severe case of neonatal hyperekplexia. ${ }^{56}$

\section{Clobazam}

Stewart et $\mathrm{al}^{32}$ successfully treated two infants with clobazam. One was started on clonazepam at the time of diagnosis but as in our case, did not tolerate the medication because of sedation and decreased feeding. The dose used was $0.25-0.3 \mathrm{mg} / \mathrm{kg} / \mathrm{d}$. Both patients had a familial form of the disorder but genetic testing was not described. Others have also reported improvement with clobazam. ${ }^{28,31}$ In contrast, Gherpelli et al found clobazam $(10 \mathrm{mg} /$ day $)$ in one patient to be ineffective. ${ }^{4}$

\section{Antiepileptic medications (excluding benzodiazepines) Phenobarbital}

Early treatments included the use of phenobarbital with conflicting reports of efficacy. Early studies report success with phenobarbital. ${ }^{1}$ However as in our case, many patients diagnosed in the neonatal period are initially treated with phenobarbital when the diagnosis of seizures is considered. In these patients it soon becomes apparent that phenobarbital does not arrest the events. $5,26-28,30$

\section{Valproic Acid}

Dooley and Andermann ${ }^{13}$ reported an adolescent who failed a trial of clonazepam but responded to valproic acid. Some report improvement with valproic $\operatorname{acid}^{27,31}$ whereas others have shown none. $5,23,27,30,31$

\section{Other}

\section{Fluoxetine}

Fluoxetine was found to be effective in one patient with sporadic hyperekplexia of adult onset that was refractory to other treatments. ${ }^{12}$

\section{Intervention during an attack}

During attacks resulting in apnea or cardiac disturbance, resuscitation may be required. Vigevano described a method used to "counteract the hypertonia" by flexing the head and legs toward the trunk forcibly during an attack of stiffness. They employed this method in a patient with great success who had episodes otherwise refractory to several treatments. ${ }^{3}$ Others have also recommended this method as it is effective, avoiding the possibility of sudden death, and is easy to perform by health care providers and families. ${ }^{4,10}$ Applying this maneuver to our patient was extremely helpful in aborting acute attacks. 


\section{Case Discussion}

Our patient was severely affected with hyperekplexia. She required resuscitation on several occasions during attacks. Her sibling, who we presume to have had the same homozygous genotype, died suddenly during a presumed startle episode at five months-of-age. It is clear from the previous descriptions of patients with SLC6A5 mutations that this gene can be responsible for severe neonatal attacks characterized by apnea that require intervention. ${ }^{17}$ Our patient experienced other comorbidities as well. She had significant feeding difficulties that were overcome with time but did require a gastrostomy tube. Her development has been affected as well with mild delay in early gross motor function in the beginning and mild delay in language.

The treatment of our patient was initially difficult and complicated by the paucity of literature that focused primarily on descriptions of the condition rather than its management, and rarely addressed cases refractory to clonazepam. After trying four different medications and their combinations, our patient was successfully discharged on a combination of clonazepam and nitrazepam.

\section{CONCLUSION}

Our understanding of the genetic basis of hyperekplexia continues to evolve. The majority of mutations are seen in the alpha subunit of the glycine receptor (GLRA1). These are usually responsible for the classic autosomal dominant form of hyperekplexia. However, mutations in this gene can also occasionally cause autosomal recessive hyperekplexia. Recently, mutations in the beta subunit of the glycine receptor (GLRB1) gene as well as gephryn (GPHN) gene, and collybistin (ARHGEF9) gene, which both encode clustering proteins, have been shown to cause the hyperekplexia phenotype. Our report provides a phenotypic description of a patient with a severe homozygous mutation in the glycine transporter 2 (SLC6A5) gene. It is imperative to investigate all patients from a molecular genetic point of view to allow genotype-phenotype correlations to emerge. This may ultimately guide management, predict prognosis and help clinicians provide families with appropriate expectations.

Startles may interfere with feeding and at times be lifethreatening, making treatment necessary. For now benzodiazepines remain the mainstay of therapy, but some patients appear to require a combination of medications. Given the rarity of the condition, large randomized control trials may not be feasible. However, at least one study was able to complete a double-blind, placebo controlled, cross-over study with four patients with a mutation in GLRA1. ${ }^{67}$ More such studies are required to help guide treatment in this disease which has significant morbidity and in some cases a significant mortality risk if left untreated.

\section{ACKNOWLEDGEMENTS}

The authors thank Prof. M. Rees and Dr. SeoKyung Chung; College of Medicine, Institute of Life Science, Swansea University for SLC6A5 gene mutation analysis and Dr. Rhys Thomas for his clinical collaboration.

\section{REFERENCES}

1. Suhren O, Bruyn GW, Tuynman JA. Hyperexplexia: a hereditary startle syndrome. J Neurol Sci. 1966;3:577-605.

2. Shahar E, Raviv R. Sporadic major hyperekplexia in neonates and infants: clinical manifestations and outcome. Pediatr Neurol. 2004;31(1):30-4.

3. Vigevano F, di CM, Dalla BB. Startle disease: an avoidable cause of sudden infant death. Lancet. 1989;333(8631):216.

4. Gherpelli JL, Nogueira AR, Jr, Troster EJ, et al. Hyperekplexia, a cause of neonatal apnea: a case report. Brain Dev. 1995;17(2): 114-6.

5. Cioni G, Biagioni E, Bottai P, Castellacci AM, Paolicelli PB. Hyperekplexia and stiff-baby syndrome: an identical neurological disorder? Ital J Neurol Sci. 1993;14(2):145-52.

6. Nigro MA, Lim HC. Hyperekplexia and sudden neonatal death. Pediatr Neurol. 1992;8(3):221-5.

7. Sharma SD, Sarna A, Mukhopadhyay S. Neonatal hyperekplexia: the Stiff-Baby syndrome. Indian Pediatr. 2006;43:539-41.

8. Kulkarni ML, Kannan B, Mathadh P. Hyperekplexia in two siblings. Indian J Pediatr. 2006;73(12):1109-11.

9. Rivera S, Villega F, de Saint-Martin A, et al. Congenital hyperekplexia: five sporadic cases. Eur J Pediatr. 2006;165(2): 104-7.

10. Pascotto A, Coppola G. Neonatal hyperekplexia: a case report. Epilepsia. 1992;33(5):817-20.

11. Tijssen MA, Vergouwe MN, van Dijk JG, Rees M, Frants RR, Brown P. Major and minor form of hereditary hyperekplexia. Mov Disord. 2002;17(4):826-30.

12. Sechi G, Sotgiu S, Valenti MP, et al. Beneficial effect of fluoxetine in a case of sporadic hyperekplexia. Clin Neuropharmacol. 2000;23(3):161-3.

13. Dooley JM, Andermann F. Startle disease or hyperekplexia: adolescent onset and response to valproate. Pediatr Neurol. 1989;5(2):126-7

14. Bakker MJ, van Dijk JG, van den Maagdenberg AM, Tijssen MA. Startle syndromes. Lancet Neurol. 2006;5(6):513-24.

15. Turecki G, Grand'Maison F, Lemieux B, Rouleau G. Hyperekplexia and the alpha1 subunit glycine receptor gene (GLRA1). Arch Neurol. 1996;53(9):836-7.

16. Rees MI, Lewis TM, Kwok JB, et al. Hyperekplexia associated with compound heterozygote mutations in the beta-subunit of the human inhibitory glycine receptor (GLRB). Hum Mol Genet. 2002;11(7):853-60.

17. Rees MI, Harvey K, Pearce BR, et al. Mutations in the gene encoding GlyT2 (SLC6A5) define a presynaptic component of human startle disease. Nat Genet. 2006;38(7):801-6.

18. Eulenburg V, Becker K, Gomeza J, Schmitt B, Becker CM, Betz H. Mutations within the human GLYT2 (SLC6A5) gene associated with hyperekplexia. Biochem Biophys Res Commun. 2006;348 (2):400-5.

19. Rees MI, Harvey K, Ward H, et al. Isoform heterogeneity of the human gephyrin gene (GPHN), binding domains to the glycine receptor, and mutation analysis in hyperekplexia. J Biol Chem. 2003;278(27):24688-96.

20. Harvey K, Duguid IC, Alldred MJ, et al. The GDP-GTP exchange factor collybistin: an essential determinant of neuronal gephyrin clustering. J Neurosci. 2004;24(25):5816-26.

21. Vergouwe MN, Tijssen MA, Shiang R, et al. Hyperekplexia-like syndromes without mutations in the GLRA1 gene. Clin Neurol Neurosurg. 1997;99(3):172-8.

22. Shiang R, Ryan SG, Zhu YZ, et al. Mutational analysis of familial and sporadic hyperekplexia. Ann Neurol. 1995;38(1):85-91.

23. Altunbasak S, Baytok V. Startle disease--hyperekplexia (two sibling cases). Seizure. 1996;5(4):313-15.

24. Hayashi T, Tachibana H, Kajii T. Hyperekplexia: pedigree studies in two families. Am J Med Genet. 1991;40(2):138-43.

25. Andermann F, Keene DL, Andermann E, Quesney LF. Startle disease or hyperekplexia: further delineation of the syndrome. Brain. 1980;103(4):985-97.

26. Leventer RJ, Hopkins IJ, Shield LK. Hyperekplexia as cause of abnormal intrauterine movements. Lancet. 1995;345(8947):461. 
27. Saenz-Lope E, Herranz-Tanarro FJ, Masdeu JC, Chacon P, Jr. Hyperekplexia: a syndrome of pathological startle responses. Ann Neurol. 1984;15(1):36-41.

28. Scarcella A, Coppola G. Neonatal sporadic hyperekplexia: a rare and often unrecognized entity. Brain Dev. 1997;19(3):226-8.

29. Doria LL, Giribaldi G, De NE, et al. A case of major form familial hyperekplexia: prenatal diagnosis and effective treatment with clonazepam. J Child Neurol. 2007;22(6):769-72.

30. Elkay M, Incecik F, Herguner MO, Leblebisatan G, Altunbasak S. Startle disease-two sibling cases. Turk J Pediatr. 2005;47(3): 275-8.

31. Brown P, Rothwell JC, Thompson PD, Britton TC, Day BL, Marsden CD. The hyperekplexias and their relationship to the normal startle reflex. Brain. 1991;114(Pt 4):1903-28.

32. Stewart WA, Wood EP, Gordon KE, Camfield PR. Successful treatment of severe infantile hyperekplexia with low-dose clobazam. J Child Neurol. 2002;17(2):154-6.

33. Beard GM. Experiments with "jumpers" of Maine. Pop Sci Monthly. 1880;18:170-8.

34. Hammond WA. Miryachit: A Newly described disease of the nervous system and its analogues. N Y Med J. 1884;39:191-2.

35. de la Tourette G. Jumping, Latah, Myriachit. Arch Neurol. 1884;8: 68-74.

36. Gastaut H, Villeneuve A. The startle disease or hyperekplexia. Pathological surprise reaction. J Neurol Sci. 1967;5(3):523-42.

37. Stevens H. "Jumping Frenchmen of Maine." Myriachit. Arch Neurol. 1965;12(3):311-4

38. Andermann F, Andermann E. Startle disease, or hyperekplexia. Ann Neurol. 1984;16(3):367-8.

39. Andermann F, Andermann E. Startle disorders of man: hyperekplexia, jumping and startle epilepsy. Brain Dev. 1988;10 (4):213-22.

40. Tijssen MA, Shiang R, van DJ, et al. Molecular genetic reevaluation of the Dutch hyperekplexia family. Arch Neurol. 1995;52(6): 578-82.

41. Tijssen MA, Padberg GW, van Dijk JG. The startle pattern in the minor form of hyperekplexia. Arch Neurol. 1996;53(7):608-13.

42. Ryan SG, Dixon MJ, Nigro MA, et al. Genetic and radiation hybrid mapping of the hyperekplexia region on chromosome 5q. Am J Hum Genet. 1992;51(6):1334-43.

43. Ryan SG, Sherman SL, Terry JC, Sparkes RS, Torres MC, Mackey RW. Startle disease, or hyperekplexia: response to clonazepam and assignment of the gene (STHE) to chromosome $5 \mathrm{q}$ by linkage analysis. Ann Neurol. 1992;31(6):663-8.

44. Shiang R, Ryan SG, Zhu YZ, Hahn AF, O'Connell P, Wasmuth JJ. Mutations in the alpha 1 subunit of the inhibitory glycine receptor cause the dominant neurologic disorder, hyperekplexia. Nat Genet. 1993;5(4):351-8.

45. Grenningloh G, Rienitz A, Schmitt B, et al. The strychnine-binding subunit of the glycine receptor shows homology with nicotinic acetylcholine receptors. Nature. 1987;328(6127):215-20.

46. Langosch D, Thomas L, Betz H. Conserved quaternary structure of ligand-gated ion channels: the postsynaptic glycine receptor is a pentamer. Proc Natl Acad Sci USA. 1988;85(19):7394-8.

47. Betz H, Kuhse J, Schmieden V, Laube B, Kirsch J, Harvey RJ. Structure and functions of inhibitory and excitatory glycine receptors. Ann N Y Acad Sci. 1999;868:667-76.

48. Kwok JB, Raskin S, Morgan G, Antoniuk SA, Bruk I, Schofield PR. Mutations in the glycine receptor alpha1 subunit (GLRA1) gene in hereditary hyperekplexia pedigrees: evidence for nonpenetrance of mutation Y279C. J Med Genet. 2001;38(6):E17.
49. Coto E, Armenta D, Espinosa R, Argente J, Castro MG, Alvarez V. Recessive hyperekplexia due to a new mutation (R100H) in the GLRA1 gene. Mov Disord. 2005;20(12):1626-9.

50. Rees MI, Andrew M, Jawad S, Owen MJ. Evidence for recessive as well as dominant forms of startle disease (hyperekplexia) caused by mutations in the alpha 1 subunit of the inhibitory glycine receptor. Hum Mol Genet. 1994:3(11):2175-9.

51. Brune W, Weber RG, Saul B, et al. A GLRA1 null mutation in recessive hyperekplexia challenges the functional role of glycine receptors. Am J Hum Genet. 1996;58(5):989-97.

52. Rees MI, Lewis TM, Vafa B, et al. Compound heterozygosity and nonsense mutations in the alpha(1)-subunit of the inhibitory glycine receptor in hyperekplexia. Hum Genet. 2001;109(3): 267-70.

53. Vergouwe MN, Tijssen MA, Peters AC, Wielaard R, Frants RR. Hyperekplexia phenotype due to compound heterozygosity for GLRA1 gene mutations. Ann Neurol. 1999;46(4):634-8

54. Langosch D, Hoch W, Betz H. The $93 \mathrm{kDa}$ protein gephyrin and tubulin associated with the inhibitory glycine receptor are phosphorylated by an endogenous protein kinase. FEBS Lett. 1992;298(2,3):113-7.

55. Eulenburg V, Armsen W, Betz H, Gomeza J. Glycine transporters: essential regulators of neurotransmission. Trends Biochem Sci. 2005;30(6):325-33.

56. Kurczynski TW. Hyperekplexia. Arch Neurol. 1983;40(4):246-8

57. Giacoia GP, Ryan SG. Hyperekplexia associated with apnea and sudden infant death syndrome. Arch Pediatr Adolesc Med. 1994; 148(5):540-3.

58. McAbee GN, Kadakia SK, Sisley KC, Delfiner JS. Complete heart block in nonfamilial hyperekplexia. Pediatr Neurol. 1995;12(2): 149-51.

59. Bellini G, Miceli F, Mangano S, et al. Hyperekplexia caused by dominant-negative suppression of glyral function. Neurology. 2007;68(22):1947-9.

60. Kimura M, Taketani T, Horie A, Isumi H, Sejima H, Yamaguchi S. Two Japanese families with hyperekplexia who have a Arg271Gln mutation in the glycine receptor alpha 1 subunit gene. Brain Dev. 2006;28(4):228-31

61. Del Giudice EM, Coppola G, Bellini G, Cirillo G, Scuccimarra G, Pascotto A. A mutation (V260M) in the middle of the M2 porelining domain of the glycine receptor causes hereditary hyperekplexia. Eur J Hum Genet. 2001;9(11):873-6.

62. Poon W-T, Au K-M, Chan Y-W, et al. Novel missense mutation (Y279S) in the GLRA1 gene causing hyperekplexia. Clin Chim Acta. 2006;364(1-2):361-2.

63. Koning-Tijssen MA, Brouwer OF. Hyperekplexia in the first year of life. Mov Disord. 2000;15(6):1293-6.

64. Siren A, Legros B, Chahine L, Misson JP, Pandolfo M. Hyperekplexia in Kurdish families: a possible GLRA1 founder mutation. Neurology. 2006;67(1):137-9.

65. Miraglia del GE, Coppola G, Bellini G, Ledaal P, Hertz JM, Pascotto A. A novel mutation (R218Q) at the boundary between the $\mathrm{N}$-terminal and the first transmembrane domain of the glycine receptor in a case of sporadic hyperekplexia. J Med Genet. 2003;40(5):e71.

66. Zhou L, Chillag KL, Nigro MA. Hyperekplexia: a treatable neurogenetic disease. Brain Dev. 2002;24(7):669-74.

67. Tijssen MA, Schoemaker HC, Edelbroek PJ, Roos RA, Cohen AF, van Dijk JG. The effects of clonazepam and vigabatrin in hyperekplexia. J Neurol Sci. 1997;149(1):63-7. 